\title{
Incidence of Strokes and Its Prognosis in Patients on Maintenance Hemodialysis
}

\author{
Kaoru Onoyama, M.D., Harumitsu KumagaI, M.D., \\ Tiaki Mishima, M.D., Hiroshi Tsuruda, M.D., \\ Suguru Tомоока, M.D., Kenichi Motomura, M.D., \\ and Masatoshi Fujishima, M.D.
}

\begin{abstract}
SUMmary
The incidences of cerebral hemorrhage $(\mathrm{CH})$, cerebral infarction (CI) and subarachnoid hemorrhage (SAH) were examined retrospectively in patients with chronic renal failure on maintenance hemodialysis, followed for 13 years in our 26 satellite dialysis centers. During 10,364 patient-years of experience (PYE), CH developed in 66, CI in 16, SAH in 3 and unclassified stroke in 5 cases. The incidence was 637 pcr $10^{5}$ PYE for $\mathrm{CH}$ and 154 for CI, the former being approximately 5 times and the latter one third of the incidence of $\mathrm{CH}$ or $\mathrm{CI}$ in the general population in Japan. Forty-six percent of fatal $\mathrm{CH}$ cases died within 24 hours and $73 \%$ within 3 days after the onset, while $13 \%$ of CI deaths died within 24 hours and $26 \%$ within 3 days. These data suggest that factors such as the regular use of heparin as an anticoagulant in hemodialysis patients or other inherent factors in these patients may increase vulnerability to $\mathrm{CH}$ and decrease the probability of CI.
\end{abstract}

\section{Additional Indexing Words :}

Cerebral hemorrhage Cerebral infarction Subarachnoid hemorrhage Endstage renal failure Cerebrovascular accident

QINCE regular maintenance hemodialysis for renal failure was introduced $\mathcal{O}$ in 1960, intracranial hemorrhage has been recognized as one important complication. Subdural hematoma in hemodialysis patients was reported first in 1969 by Leonard et al $^{11}$ and subsequently intracerebral and subarachnoid hemorrhages were noted by many investigators. ${ }^{21-5)}$ Patients

From the Second Department of Internal Medicine, Faculty of Medicine, Kyushu University, Fukuoka, Japan.

Supported by a grant from the Glomerular Injury Research Committee, Division of Public Health and Welfare, Japan.

Address for reprint: Dr. Kaoru Onoyama, Second Department of Internal Medicine, Faculty of Medicine, Kyushu University, Maidashi 3, Higashi-ku, Fukuoka City 812, Japan.

Received for publication December 28, 1985. 
aged 35 to 54 , who underwent hemodialysis and kidney transplantation, died 50 times more frequently than did the general population of France in 1978.2) Cerebral hemorrhage $(\mathrm{CH})$, subarachnoid hemorrhage $(\mathrm{SAH})$ and cerebral infarction(CI) are not uncommon in these hemodialysis patients. Annual death rates from cerebrovascular accidents in these patients were reported as $13.7 \%$ in Europe in $1978^{2}$ and $14.2 \%$ in Japan in 1983. ${ }^{3)}$ During 5 years of treatment with maintenance hemodialysis, Siddiqui et $\mathrm{al}^{(4)}$ found that 4 patients died from intracranial hemorrhage among 41 in the sample. A prospective study of 1,453 chronic hemodialysis patients in 33 French dialysis centers between 1972 and 1978 demonstrated that 198 cases died during the follow-up period, of which 35 cases or $17.7 \%$ died from strokes. ${ }^{5}$ ) Given recent increases in the number of the patients who are introduced into maintenance hemodialysis, it is important to assess the incidence of stroke and its prognosis during prolonged treatment. This paper investigates the incidence of strokes in a large number of maintenance hemodialysis patients in order to form a basis for assessing risk factors affecting the development of strokes.

\section{Patients AND Methods}

The study population consisted of patients treated with maintenance hemodialysis from December 1971 to December 1984 in our 26 satellite dialysis centers. The numbers of patients who were maintained at the end of December in each dialysis center were tabulated for each year and the study comprises a total of 10,364 patient-years of experiences (PYE) over the period 1971-1984. The development of strokes was examined retrospectively in this patient pool. $\mathrm{CH}, \mathrm{CI}$ and $\mathrm{SAH}$ were included as strokes but a transient ischemic attack or hypertensive encephalopathy was excluded. The diagnosis of stroke was made clinically with the aid of CT scans and lumbar puncture. Autopsy data confirmed the diagnosis in some cases. An unclassified stroke was registered as cerebrovascular disease (CVD). When the patients died within 6 months of the onset of strokes, without an other major cause of death, they were listed as stroke death. There were 7 cases of $\mathrm{CH}$ and 2 cases of CI where the exact time interval from the last hemodialysis treatment to the onset of stroke was not determined because of incomplete records. The time of onset of a stroke was unclear in 1 case of CVD.

Hemodialysis was performed 3 times per week in 5 to 6 hour sessions, using a subcutaneous arterio-venous fistula. There were no differences in the settings for dry weight, levels of uremia and antihypertensive treatment in the centers covered by the study. Data were expressed as mean $\pm S D$ and 
calculated by one-way analysis of variance prior to an unpaired Student's t-test. The Chi-square test was also used for statistical analysis. P values less than $5 \%$ were considered to be significant.

\section{Results}

Among 10,364 PYE, there were 90 cases of strokes (66 with $\mathrm{CH}$, 16 with GI, 3 with SAH and 5 with GVD). Patient profiles of these cases are listed in Table I. $\mathrm{CH}$ comprised $73 \%$ of all the strokes and CI comprised $18 \%$. The average age of the patients did not differ between CH(53 yrs) and CI (59 yrs), but it was significantly higher in $\mathrm{CH}(\mathrm{p}<0.05)$ and $\mathrm{CI}(\mathrm{p}<0.01)$ than in $\mathrm{SAH}(38 \mathrm{yrs})$. The duration of hemodialysis treatment prior to strokes ranged from 18 to 61 months, but the differences were not statistically significant among the groups of patients. Fifty-five of $66 \mathrm{CH}$ cases and 8 of $16 \mathrm{CI}$ cases died from the stroke, and all $3 \mathrm{SAH}$ and 4 of 5 GVD cases were fatal as well.

The incidence of strokes per $10^{5} \mathrm{PYE}$ is shown in Table II. The incidence of $\mathrm{CH}$ was 637 per $10^{5}$ PYE, being 4 times greater than the incidence of CI (154). By contrast, the incidence of SAH was very low (29).

The time interval from the end of the last hemodialysis session to the

Table I. Sex, Age and Duration of Hemodialysis (HD) in Maintenance HD Patients Who Developed Stroke

\begin{tabular}{|c|c|c|c|c|c|c|}
\hline \multirow{2}{*}{$\begin{array}{l}\text { Type of } \\
\text { stroke }\end{array}$} & \multirow{2}{*}{$\begin{array}{l}\text { No of } \\
\text { cases }\end{array}$} & \multicolumn{2}{|c|}{ Sex } & \multirow{2}{*}{ Age (yrs) } & \multirow{2}{*}{$\begin{array}{l}\text { Duration of } \\
\text { HD (mos) prior } \\
\text { to stroke }\end{array}$} & \multirow{2}{*}{ No of deaths } \\
\hline & & male & female & & & \\
\hline $\mathrm{CH}$ & 66 & 43 & 23 & $53 \pm 11 * *$ & $40 \pm 45$ & $55 \quad(83 \%)$ \\
\hline CI & 16 & 10 & 6 & $59 \pm 12 *$ & $23 \pm 27$ & $8 \quad(50 \%)$ \\
\hline SAH & 3 & 2 & 1 & $38 \pm 9$ & $61 \pm 22$ & $3(100 \%)$ \\
\hline \multirow[t]{2}{*}{ CVD } & 5 & 3 & 2 & $55 \pm 8$ & $18 \pm 20$ & $4 \quad(80 \%)$ \\
\hline & 90 & 58 & 32 & $53 \pm 12$ & $39 \pm 41$ & 70 \\
\hline
\end{tabular}

$\mathrm{CH}=$ cerebral hemorrhage $\mathrm{CI}=$ cerebral infarction ; $\mathrm{SAH}=$ subarachnoid hemorrhage $\mathrm{GVD}=$ unspecified stroke. Values are mean $\pm \mathrm{SD}$.

* $\mathrm{p}<0.05, * * 0.01$ (vs SAH).

Table II. Annual Incidence of Strokes per 100,000 Patient-years of Experience

\begin{tabular}{cc}
\hline Type of stroke & Incidence \\
\hline CH & 637 \\
CI & 154 \\
SAH & 29 \\
CVD & 48
\end{tabular}


Table III. Time Interval from the End of the Last Hemodialysis (HD) to the Onset of Stroke

\begin{tabular}{l|c|c|c|c}
\hline Type of stroke & $\begin{array}{c}\text { No of } \\
\text { cases }\end{array}$ & $\begin{array}{c}\text { Time interval } \\
\text { (hrs) }\end{array}$ & $\begin{array}{c}\text { During or within } \\
6 \mathrm{hrs} \text { after HD }\end{array}$ & $\begin{array}{c}6 \text { hrs or more } \\
\text { after HD }\end{array}$ \\
\hline CH all & 59 & $21 \pm 27$ & $23(39 \%)$ & $36(61 \%)$ \\
survived & 10 & $24 \pm 19$ & $3(15 \%)$ & $7(19 \%)$ \\
died & 49 & $21 \pm 23$ & $20(85 \%)$ & $29(81 \%)$ \\
CI all & 14 & $11 \pm 21$ & $9(64 \%)$ & $5(36 \%)$ \\
survived & 7 & $2 \pm 5^{*}$ & $6(67 \%)$ & $1(20 \%)$ \\
died & 7 & $25 \pm 26$ & $3(23 \%)$ & $4(80 \%)$
\end{tabular}

Strokes developed during HD were calculated as 0 hour.

Values are mean \pm SD.

* $p<0.05$ vs cases died in CI. Seven cases in CH and 2 in CI were excluded because the exact time of the last $\mathrm{HD}$ was undetermined.

Table IV. Length of Survival (hrs) of the Death Cases Following Strokes

\begin{tabular}{c|c|c|c}
\hline Type of stroke & No of cases & Length of survival & Range \\
\hline CH & 55 & $72 \pm 128$ & $2-720$ \\
CI & 8 & $436 \pm 1151$ & $22-3600$ \\
SAH & 3 & $120 \pm 70$ & $19-192$ \\
CVD & 3 & $96 \pm 115$ & $109-288$
\end{tabular}

Values are mean $\pm \mathrm{SD}$. One case in GVD was excluded because the exact time of onset was undetermined.

onset of stroke is shown in Table III. When the stroke developed during hemodialysis, the interval was designated 0 hour. Average values for the time interval were 21 hours for $\mathrm{CH}$ and 11 hours for $\mathrm{CI}$, respectively; the difference was not significant. However, the time interval was significantly shorter in CI cases who survived than in those who died from the attack within 6 months $(p<0.05)$. Strokes developed during or within 6 hours of the previous hemodialysis session in $39 \%$ of $59 \mathrm{CH}$ cases, and $64 \%$ of $14 \mathrm{CI}$ cases. The remaining $\mathrm{CH}$ and $\mathrm{CI}$ had attacks at least 6 hours after the session. Twenty of $23 \mathrm{CH}$ cases that were manifest within 6 hours of dialysis were fatal $(87 \%)$, while 6 of 9 cases with CI survived $(67 \%)$. By contrast, 7 of $36 \mathrm{CH}$ cases that had developed at least 6 hours after dialysis survived for more than 6 months, while 4 of 5 cases with CI died within 6 months.

The average survival period of the patients who died within 6 months after stroke is shown in Table IV. The survival time was $72 \pm 128$ (SD) hours for $55 \mathrm{CH}$ cases and $436 \pm 1151$ hours for 8 CI cases, respectively (not significant). As tabulated in Table $\mathrm{V}, 46 \%$ of $\mathrm{CH}$ patients died within 24 hours after the onset and, cumulatively $73 \%$ were dead within 3 days and 
Table V. Distribution of the Time Intervals from the Stroke-onset to Death in the Fatal Cases

\begin{tabular}{c|rrrr}
\hline \multirow{2}{*}{ Type of stroke } & \multicolumn{4}{c}{ Died after the onset (day) } \\
\cline { 2 - 5 } & $<1$ & $1-3$ & $3-30$ & $30<$ \\
\hline CH & $25(46 \%)$ & $15(27 \%)$ & $15(27 \%)$ & 0 \\
CI & $1(13 \%)$ & $1(13 \%)$ & $4(50 \%)$ & $2 *(24 \%)$
\end{tabular}

$\chi^{2}=17.4 . \quad \mathrm{p}<0.01$.

* 2 cases died at 60 and 150 days, respectively.

$100 \%$ within 1 month of hemorrhage. By contrast, $13 \%$ of the CI patients died within 24 hours, $26 \%$ within 3 days and $76 \%$ within 1 month. This difference in survival time between $\mathrm{CH}$ and $\mathrm{CI}$ patients was significant by a Chi-square test $(\mathbf{p}<0.01)$, indicating that $\mathrm{CH}$ patient died much earlier than CI patients.

\section{Disqussion}

The incidence of strokes has not yet been reported in a large number of maintenance hemodialysis patients. However the present results can be compared with the data obtained by field surveys in epidemiological studies. Robins and Baum, ${ }^{6}$ ) who summarized previous reports in the literature, stated that the incidence of $\mathrm{CH}$ in the U.S.A. and Europe ranged between 17 to 88 per $10^{5}$ PYE. On the other hand, in the Japanese general population, the incidence has been reported to be $120^{7)}$ or $212^{81}$ per $10^{5}$ PYE in the $1970 \mathrm{~s}$. Thus, the incidence of $\mathrm{CH}$ in hemodialysis patients was 3 to 5 times higher than the incidence in the general population, indicating that this class of patients is at greater risk.

Possible causative factors for intracranial hemorrhages in these patients include hypcrtension, systemic heparinization, ultrafiltration to treat fluid accumulation, poor platelet adhesion and vascular access infection ${ }^{9 /, 10)}$; the potential roles of hypertension and anticoagulant have been especially emphasized. According to our previous report, $58 \%$ of maintenance hemodialysis patients were hypertensive, ${ }^{11}$ while the present study found that $66.7 \%$ of hemodialysis patients with $\mathrm{CH}$ had hypertension. Recent advances in the treatment of hypertension may decrease the death rate from stroke in the first 6 months of dialysis into a tenth of the figure in the mid-1960s.9) However, a majority of the hemodialysis patients still have hypertension, which may be partly responsible for a higher incidence of $\mathrm{CH}$ in hemodialysis patients.

In regular hemodialysis a high dose of heparin is given 3 times a week, 
4 to 5 hours each during hemodialysis. The anticoagulant effects of heparin persist for 6 hours after administration. Siddiqui et $\mathrm{al}^{4)}$ have reported a prolonged clotting time as a causative factor of death in 3 out of 4 cases of intracranial hemorrhage. Even in the absence of hemodialysis, $31 \%$ of the sudden deaths from $\mathrm{CH}$ were found to be on long-term oral anticoagulant therapy. ${ }^{12}$ However, the shorter survival time suggests that $\mathrm{CH}$ in hemodialysis patients is clinically more severe. In fact, CT scans from this group of patients demonstrated large hematoma in the cerebral hemispheres or in the brain stem. ${ }^{13)}$ Systemic heparinization seems to be an important factor in the poor prognosis of these patients.

According to epidemiological studies in Japan, the incidence of CI was $470^{77}$ or $586^{8}$ per $10^{5} \mathrm{PYE}$, whereas it was 154 per $10^{5} \mathrm{PYE}$ in hemodialysis patients. Thus, there is a major difference in the incidence of $\mathrm{CH}$ and $\mathrm{CI}$ in hemodialysis patients and the general population, with a higher incidence of $\mathrm{CH}$ and a lower incidence of CI in these patients. It is suggested that heparinization, rather than hypertension plays a more important role in either the development of $\mathrm{CH}$ or the prevention of $\mathrm{CI}$ in the hemodialysis patients. In the present study, all cases of SAH died but the small sample size precludes further analysis of the data. Thus, further studies of this less common group of patients are needed to determine possible risk factors for $\mathrm{SAH}$ as a function of hemodialysis.

\section{ACKNOWLEDGMENTS}

The authors wish to thank all the doctors and the medical associates in the Dialysis Centers for their cooperation.

\section{REFERENCES}

1. Leonard $\mathrm{CD}$, Weil E, Scribner BH: Subdural hematomas in patients undergoing haemodialysis, Lancet 2: 239, 1969

2. Brunner FP, Brynger H, Chantler C, Douckerwolcke RA, Hathaway RA, Jacobs C, Selwood $\mathrm{NH}$, Wing AJ: Combined report on regular dialysis and transplantation in Europe, IX, 1978. Proc EDTA 16: 4, 1979

3. Japanese Dialysis Organization: Annual Report on Dialysis in Japan, 1983 (in Japanese)

4. Siddiqui JY, Fitz AE, Lawton RL, Kirkendall WM: Causes of death in patients receiving long-term hemodialysis. JAMA 212: 1350, 1970

5. Degoulet P, Legrain M, Reach I, Aime F, Devries C, Rajas P, Jacobs C: Mortality risk factors in patients treated by chronic hemodialysis. Nephron $31: 103,1982$

6. Robins M, Baum HM: Incidence. Stroke 12 (suppl 1): 45, 1981

7. Ueda K, Omae T, Hirota Y, Takeshita M, Katsuki S, Tanaka K, Enjoji M: Decreasing trend in incidence and mortality from stroke in Hisayama residents, Japan. Stroke 12: 154, 1981

8. Tanaka H, Ueda $\mathrm{Y}$, Hayashi $M$, Date $\mathrm{C}$, Baba T, Yamashita H, Shoji $H$, Tanaka $\mathrm{Y}$, Owada K, Detels R: Risk factors for cerebral hemorrhage and cerebral infarction in a Japanese 
rural community. Stroke 13: 62, 1982

9. Kerr DNS: Clinical and pathophysiologic changes in patients on chronic dialysis: The central nervous system. Adv Nephrol 9: 109, 1980

10. Nessenson AR, Levin ML, Klawans HL, Nausieda PL: Neurological sequelae of end stage renal disease (ESRD). J Chron Dis 30: 705, 1977

11. Omae T, Onoyama K: Volume factors in hypertension in end stage renal failure. Proc 2nd Asian Pacific Congr Nephrol, p 87, 1983

12. Phillips LH II, Whisnant JP, Reagan TJ: Sudden death from stroke. Stroke 8: 392, 1977

13. Onoyama K, Ibayashi S, Nanishi F, Okuda S, Oh Y, Hirakata H, Nishimura Y, Fujishima $\mathrm{M}$ : Cerebral hemorrhage in patients on maintenance hemodialysis: $\mathrm{CT}$ analysis of 25 cases. European Neurology (in print) 